\title{
MOORE AND CALLAHAN'S "LAW AND LEARNING THEORY": A PSYCHOLOGIST'S IMPRESSIONS*
}

\author{
BY CLARK L. HULL $\dagger$
}

THE primary objective of the founders of the Institute of Human Relations was to contribute to an integrated development of the biological and social sciences. Such a program necessarily includes in its scope the broad fields of individual and social behavior. Portions of these two major fields are conceived to combine with each other and with portions of other basic sciences to form special disciplines which constitute important fields of practical interest. Prominent among these disciplines are jurisprudence, political science, economics, sociology, cultural anthropology, penology, psychiatry, and education. The Institute has fostered a number of investigations in the field of jurisprudence. To this series the Moore and Callahan study is a contribution of special significance.

In the early days of the Institute of Human Relations it became painfully evident that isolated studies in the various social sciences did not constitute a scientific integration. It must be remembered in this connection that an integrated approach to the social sciences as a whole had never before been attempted. After considerable fumbling, a formal resolution of this critical problem was found in a systematic theory of behavior comprehensive enough to furnish an integrative matrix for all of the social sciences. This discovery also furnished a happy solution to the administrative dilemma of how to secure an integration of the work of numerous investigators and yet. retain the freedom of all; for without the latter, vital scientific research cannot be carried on.

The difficulties encountered in applying this administrative principle have been great. For example, despite the fact that our knowledge concerning behavior was considerable, it was fragmentary, and had never been comprehensively formulated as a systematic set of principles. Moreover, if and when such a comprehensive set of principles should be formulated, a second formidable difficulty would be encountered at the higher levels of application because no scientist could be found who would be competent in both the basic and the applied discipline, or who, being competent in one, would be willing or able to acquire a working knowledge of the other. The magnitude of this difficulty may be realized when it is recalled that to become a master of even one field of the social sciences

\footnotetext{
* Moore and Callahan, Law and Learning Theory: A Study in Legal Control (1943) 53 Y ALE L. J. 1; also separately printed under the same title by the Yale Law Journal Co., Inc., with a foreword by Mark A. May.

† Professor of Psychology, Institute of Human Relations, Yale University.
} 
takes the better part of a lifetime. In the Moore-Callahan study this type of obstacle has been largely surmounted. This means that in the present state of our ignorance concerning ultimate behavioral laws, such a work as the one here under consideration must be somewhat in the nature of a courageous tour de force, and, as such, must be expected to display characteristic defects. For exactly the same reason, also, it is probable that no man now living is competent adequately to judge its ultimate merits and defects. The reviewer trusts that the following comments will be read with this obvious limitation constantly in mind. ${ }^{1}$

At the outset one or two unimportant defects may be mentioned. There are a few misprints, such as the form of two equations which appear on page 28. In each of these the negative exponent of 10 is placed nearly on a level with the 10 itself; the context, however, is such that any reader who would care to use the equations would hardly be misled. Another trivial defect of a quite different type is found in Figure 13; here, apparently, all of the points plotted are placed ten units below where they should be with respect to the scale at the left. But this also is not likely to mislead, since the tabular values from which the figure is plotted are given clearly in the columns marked " $C$ " of Table 3, pages 100-02.

Turning to the statistical treatment of the empirical results arising from the several studies reported in the monograph, we find much which is admirable. It is evident that the data have been tabulated with great care and that much thought has been lavished on their analysis. Moreover, the method of fitting objective equations to the various functions emerging from the empirical evidence is strongly to be commended. The meticulous care with which control observations were made before the introduction of the causal factor in each study renders the statistical analysis fruitful in significant dynamic relationships.

The simplest and most easily interpreted of the studies is that which concerns a rotary traffic arrangement at a complex street intersection." It was found that signs commanding drivers to keep to the right of an oval painted on the pavement were obeyed to a considerable extent, and that the extent to which obedience was observed approached quite closely an inverse linear function ${ }^{3}$ of the extent of the required deviation from the normal path (shortest distance) across the intersection. This, as the writers point out, ${ }^{4}$ is in complete conformity with theoretical behavior

1. The reviewer's only technical knowledge of the law was obtained many years ago from a college course in Constitutional Law and a summer's undirected study of Cooley's Blackstone. He has, however, had the advantage of repeated conversations with Professor Moore during the progress of the investigation here being reviewed, particularly during the period when the data were being analyzed.
2. Pp. 53-60.
3. Figure 55, p. 59.
4. Pp. 85-87. 
expectation that organisms will take the shortest practicable path to their goal or point of reinforcement. On the basis of behavior principles it is also to be expected that the effect of a printed imperative will be greater upon certain drivers than upon others, depending on how much anxiety (secondary motivation) is aroused as determined by variable individual constitution and life history. Thus there is a variable conflict or competition between (1) the motivation which leads to the attainment of the original goal as soon and as economically as possible and (2) the motivation produced by the anxiety.

Moreover, it is to be presumed that in any individual the greater the conformity to the command of the sign, the less will be the amount of anxiety. In the rotary traffic situation there lie two lateral motivational gradients: (1) a major positive goal gradient, its maximum lying along a straight line from one street to another and diminishing in each direction, and (2) an anxiety gradient produced by the sign. This negative or avoidance gradient presumably has its maximum at the oval and decreases toward a point of minimum anxiety some place at the right. ${ }^{5}$ Clearly, the driver's course across this intersection will fall at the locus of the series of points at which the difference between these two opposed gradients has the largest positive value. This point of maximum positive value will vary from driver to driver, depending upon the relative strengths of the two motivations. If one driver has a strong motivation to reach his destination and a relatively weak potential anxiety from the disregard of the police sign, his path across the intersection will be comparatively little diverted from a straight line. On the other hand, a driver who happens to be in no great haste, or who is especially subject to anxiety from yiolating police signs, may drive far out in complete conformity to the command of the sign. The results shown in Moore and Callahan's table ${ }^{8}$ represent a composite of the relative strengths of positive and negative motivations in a fairly random sample of the driving population of New Haven.

A somewhat less simple investigation was that concerned with the effect on drivers of tagging cars which remained parked for various intervals beyond the time specified as the limit by the city ordinances, as indicated by permanently placed street signs. Statistical problems of some complexity arose as to the proper interpretation of the data secured, owing in part to the fact that any parking space left vacant by drivers whose cars had been tagged would be occupied in more or less unknown amounts by other drivers wandering around in search of a place to park who would not

5. Unfortunately we do not yet know very much about the exact characteristics of either of these gradients. It is possible that a careful analysis of the data contained in the table, p. 56, might throw considerable light on this important matter. That, however, extends beyond the range of the present review.

6. P. 56. 
have been able to park in the observed area had not the tagging occurred. Despite these and other difficulties, the writers are probably justified in their contention that the tagging of the cars had little influence on the behavior of any drivers except those of the cars actually tagged, and that these latter drivers showed a marked tendency to avoid parking in this area. This tendency is convincingly accounted for by Moore and Callahan as resulting from the creation in the drivers whose cars were tagged of a new and specific anxiety motivation.

We turn now to the more elaborate parking studies concerned with the effects of posting signs designed to limit the duration of parking. In experimental situations, it is customary to report the functional relationships between the various quantitative effects observed and the quantitative aspects of the cause introduced. For this reason one would naturally expect to find an equation expressing the shift in parking times as a function of the times stated in the several city ordinances involved. The reader is, accordingly, somewhat surprised to see that the major part of the analysis is based, not directly upon the ordinance times of permissible parkings (the causal factor introduced into the situation) but, rather, upon certain internal relationships among the cumulative distribution of parkings as influenced by ordinance times.

As a matter of fact, a study of various of the published tables ${ }^{\top}$ shows that there is an indication of such an empirical relationship between the introduced cause and the behavioral effects. From the data in question the reviewer plotted a curve which reveals a tolerably regular functional relationship (though somewhat less regular than the relationship plotted by Moore and Callahan in their Figure $21^{8}$ ) between ordinance time and the mean time at which the distribution of parkings showed the first indications of response to the posted equivalents of the ordinance; the curve so plotted is fairly comparable, point for point, with the illuminating graph shown in Figure 21. Roughly speaking, the two graphs present the same picture. So far as one can tell from the limited number of points on the newly plotted graph, the most probable relationship between ordinance time and the time of the first indication of the parkers' response to the posted statement of it is approximately linear, much as shown in the published figure. By inspection, the equation of the reviewer's graph representing the relationship between the two times is approximately,

$$
t^{\prime}=2.3 t+1
$$

where $t$ is the permissible parking time in minutes according to the city ordinance, and $t^{\prime}$ is the parking duration in minutes at which the first indication of response to the posted sign became evident in the cumulative distributions of parking times. Thus $t^{\prime}$ is the duration corresponding to

7. See especially the table at p. 21.

8. P. 22. 
Moore and Callahan's "Point," symbolized by them as $p$ in units of the cumulative percentage of the spontaneous or unregulated (control) series of observations. The above equation means in effect that as a whole the parkers did not begin to respond to the posted ordinance until a period had elapsed which was, on the average, about 2.3 times the duration specified in the ordinance as the parking limit.

When one stops to consider this outcome, it is at first somewhat surprising for several reasons. True enough, as Moore and Callahan point out, ${ }^{9}$ there is known to be a relativity of time-interval judgments in the sense that long intervals are less accurately judged than small ones. But at this point a paradox enters. In the experiments by which was determined the above-mentioned law of the relativity of time judgments, the subjects making the experimental judgments had no access to time-pieces; otherwise, the precision of time determinations would have been mainly a function not of the time interval being measured, but of the accuracy of the time-pieces consulted and of the precision of reading the time indicated by the time-pieces. It is to be assumed, of course, that nearly all of the drivers carried reasonably accurate time-pieces. In view of these considerations we seem forced to the conclusion that the street signs as stimuli did not evoke enough anxiety regarding possible enforcement of the ordinance to cause the drivers to consult their watches. This, of course, throws us back substantially to the relativity position taken by Moore and Callahan.

Even so, there remains the question of why in all cases the errors in time judgment should, upon the whole, have been so uniformly in one direction, that is, in effect of judging the time parked as less than it was in fact. It is difficult to believe that this is merely a phenomenon of relativity in time judgments. It seems much more likely that it is a reflection of the habits of successful (and so, reinforced) disregard of law produced by our characteristically lax customs of law enforcement. Nevertheless, it is truly astonishing that that small per cent of the parking poptulation which is the most sensitive to anxiety from law violation should not have responded to an unambiguous notice until more than twice the maximum time stipulated by the ordinance had elapsed. It is difficult to believe that a few of the more conscientious or timid individuals even in our blasé culture would not have consulted their watches and so have observed the ordinance exactly. Accordingly, if sufficiently large samples of data were to be secured and sufficiently delicate methods of detecting small effects were to be employed, it is believed that the behavior of the individuals in question would locate Moore and Callahan's "Point" $(p)$ rather close to the time specified in the ordinance. For example, on the basis of general behavior principles it is to be expected that if really severe penalties for

9. Pp. 74 et seq. 
violation of the ordinance were uniformly inflicted for all violations as soon as they occurred, many drivers in their anxiety to aroid a possible ordinance violation would make certainty doubly certain by reducing their parking times to periods less than the ordinance time, in which case $p$ would stand at a value appreciably less than that of $t$.

There is some evidence of the correctness of the theoretical expectation just suggested, despite the fact that Moore and Callahan publish graphs which they regard as showing that the percentage distribution of the parkings for times less than those corresponding to their "Point" does not differ in their "regulated" and "unregulated" distributions. A careful examination of their published tables reveals some indications of such a response as might reasonably be expected on the part of very conscientious or timid drivers. A rough measure of change in a distribution as a whole lies in the shift of the mode or point of greatest frequency in the distribution, frequency categories remaining constant. In a study of the tables of Appendix $\mathrm{B},{ }^{10}$ a definite suggestion of such a shift was found. Of these ten tables, a shift such as is to be expected occurs in seven; in two there is no shift; and in one there is a shift, but it is in the opposite direction. The facts are summarized briefly in the following table:

\begin{tabular}{|c|c|c|c|c|}
\hline \multirow{2}{*}{$\begin{array}{c}\text { Parking study } \\
\text { number }\end{array}$} & \multirow{2}{*}{$\begin{array}{c}\text { Ordinance parking } \\
\text { time linhit }\end{array}$} & \multicolumn{2}{|c|}{$\begin{array}{c}\text { Time interial of parling fre- } \\
\text { quency maximum }\end{array}$} & \multirow{2}{*}{$\begin{array}{l}\text { Agrecnent with } \\
\text { expectation }\end{array}$} \\
\hline & & $\begin{array}{c}\text { Before posting } \\
\text { of sigis }\end{array}$ & $\begin{array}{l}\text { After posting } \\
\text { of signt }\end{array}$ & \\
\hline $\begin{array}{l}\text { I. } \\
\text { III. } \\
\text { III. } \\
\text { IV. } \\
\text { VI. } \\
\text { VII. } \\
\text { VIII. } \\
\text { IX. } \\
\text { X. }\end{array}$ & $\begin{array}{r}2 \\
2 \\
2 \\
2 \\
15 \\
15 \\
30 \\
30 \\
60 \\
60\end{array}$ & $\begin{array}{l}2-3 \text { minutes } \\
1-2 \text { minutes } \\
1-2 \text { minutes } \\
4-5 \text { minutes } \\
5-6 \text { minutes } \\
2-3 \text { minutes } \\
3-4 \text { minutes } \\
4-5 \text { minutes } \\
1-2 \text { minutes } \\
8-9 \text { minutes }\end{array}$ & $\begin{array}{c}0-1 \text { minutes } \\
0-1 \text { minutes } \\
0-1 \text { minutes } \\
2-3 \text { minutes } \\
3-4 \text { minutes } \\
1-2 \text { minutes } \\
2-3 \text { minutes } \\
\text { 3-4, } 5-6 \text { minutes } \\
1-2 \text { minutes } \\
11-12 \text { minutes }\end{array}$ & $\begin{array}{l}+ \\
+ \\
+ \\
+ \\
? \\
? \\
+\end{array}$ \\
\hline
\end{tabular}

The theoretical expectation is still further confirmed by the distribution of the ordinance times of the studies in question; without exception the modal shifts in the direction of a shorter time fall in the studies involving the shorter ordinance times, the breakdown of the rule occurring only in the studies involving the longer ordinance times. It is possible that such a small effect originating at a time so remote from that of the mode would be dissipated before its influence could spread so far.

In this connection there remains a tantalizing question. One wonders why, if the parkers took a chance on such an extensive violation of the ordinance, they should be influenced by it at all-and in all ten studies

10. Pp. 94-116. 
there is clear evidence that they really were influenced. This paradox may be accounted for by the general practice in the American culture for the authorities practically to wink at small violations, but to punish gross violations with increasing certainty and severity.

In general summary of the empirical aspects of the monograph, it may be said that the Moore-Callahan investigation was the logical outcome of a wholly naturalistic conception of the law, that it was planned and executed with careful provision for control observations which would make possible a determination of the effect on human behavior of certain legal enactments and related administrative procedures, that the resulting datir were meticulously analyzed for effects of the impact of the several enactments and administrative procedures, and, finally, that the results of this analysis have been interpreted in terms of a general objective theory of behavior. In view of the novelty of the undertaking it is not surprising that difficulties were encountered; indeed, it is truly surprising that these were as small as they actually proved to be. Of major significance in this pioneering investigation is the fact that it has demonstrated that jurisprudence has a legitimate place in a quantitative natural-science conception of the social sciences. If one should be tempted to criticize the investigation on the ground of the superficially commonplace or trivial nature of the phenomena under observation, it is only necessary to recall that when the action of natural law is the primary concern, nothing is trivial which reveals unambiguously and quantitatively the results of its operation. The rolling of marbles down an inclined plane or the falling of bricks from a tower are trivial events in themselves, but when such events were carefully measured by Galileo, they led not only to a discovery of the quantitative laws of motion, but, ultimately, to a truly revolutionary change in man's conception of the physical world. It is believed that the Moore-Callahan investigation will find a permanent place in the literature of the present scientific revolution in which the social (behavioral) sciences are gradually taking on the characteristics of true natural science.

As a continuation of the same line of thought, we may consider briefly the relationship and bearing of the Moore-Callahan investigation to the philosophy of law. The reader may well have conjectured from the opening paragraphs of the present series of comments that there is implicit in the program of the Institute of Human Relations a very definite philosophy which naturally extends to what is known as a philosophy of law. Very briefly, this is the basic hypothesis that there are ultimate laws to which all mammalian behavior conforms, that these laws may be discovered and formulated quantitatively as equations, and that the forms of these equations are the same for all individuals and species, the differences lying only in certain quantitative constants (coefficients, exponents, etc.) which appear in the equations. Such assumptions have long been 
commonplace in the natural sciences, but they are not yet fully recognized in the social sciences in general and in the law in particular. Thus law is conceived as a special form of human engineering in which the science of behavior plays the role which physics plays in ordinary engineering, and in which statutes are regarded as verbal or symbolic inventions designed to mediate certain behavioral ends, much as mechanical, chemical, or electrical inventions are designed to attain certain physical ends. Just as many successful physical inventions were achieved before the discovery of the ultimate physical principles upon which their operation depends, so, many successful laws have been, and will continue to be, enacted in the absence of any formalized knowledge of the elementary behavior principles upon which their success depends.

Professor Moore has given a vigorous statement of this philosophy in his contribution to an important symposium on legal philosophy, where he elaborates the natural-science approach in a sophisticated manner. It is encouraging to note that with few exceptions the writers represented in that work are in general harmony with Professor Moore's views, only one being definitely antagonistic. The monograph before us is an original, fearless, and convincing exemplification of the implementation of this philosophy.

11. See article by Moore and Callahan in MIY Prilosopny of Law (1941) 201. 